\title{
CONTRIBUIÇÕES DO DESENHO DA FIGURA HUMANA PARA A AVALIAÇÃO DA IMAGEM CORPORAL NA ANOREXIA NERVOSA
}

\author{
HUMAN FIGURE DRAWING CONTRIBUTIONS \\ FOR BODY IMAGE ASSESSMENT IN ANOREXIA NERVOSA
}

Rodrigo Sanches Peres ${ }^{1}$, Manoel Antônio dos Santos²

\begin{abstract}
${ }^{1}$ Psicólogo. Pós-graduando (Doutorado). ${ }^{2}$ Docente. Bolsista de Produtividade em Pesquisa do CNPq. Departamento de Psicologia e Educação. Faculdade de Filosofia, Ciências e Letras de Ribeirão Preto - USP.

Correspondência: Rodrigo Sanches Peres. Rua Jesuíno de Arruda, 2753 - Centro. CEP 13560-060 - São Carlos - SP - Brasil

e-mail: rodrigosanchesperes@yahoo.com.br
\end{abstract}

Peres RS, Santos MA. Contribuições do Desenho da Figura Humana para a avaliação da imagem corporal na anorexia nervosa. Medicina (Ribeirão Preto) 2006; 39 (3): 361-70.

RESUMO: O presente estudo foi desenvolvido com o intuito de avaliar a imagem corporal de portadoras de anorexia nervosa. Optou-se por utilizar como instrumento o Desenho da Figura Humana (DFH) por se tratar de uma técnica projetiva gráfica que possibilita a investigação dos processos psicológicos profundos e, conseqüentemente, remete à representação mental que o sujeito possui de si mesmo. Foram avaliadas 10 mulheres anoréxicas vinculadas ao Grupo de Assistência em Transtornos Alimentares (GRATA) do HC-FMRP-USP. O material coligido foi avaliado em conformidade com os procedimentos descritos pela literatura científica especializada. Os resultados obtidos indicam que parte das mulheres avaliadas apresenta uma imagem corporal negativa, permeada claramente por sentimentos de inferioridade, inadequação e insegurança. Em contrapartida, algumas das participantes do presente estudo projetaram nos desenhos uma imagem corporal idealizada, influenciada diretamente por mecanismos de defesa compensatórios. Tais resultados indicam que o DFH pode ser considerado uma técnica profícua para a avaliação da imagem corporal na anorexia nervosa, de modo que se destaca como uma valiosa alternativa aos instrumentos psicométricos usualmente empregados com essa finalidade.

Descritores: Anorexia Nervosa. Imagem Corporal. Avaliação Psicológica.

\section{1- INTRODUÇÃO}

\section{1- Aspectos psicopatológicos da anorexia ner- vosa}

A anorexia nervosa é um transtorno alimentar desencadeado e perpetuado por fatores biológicos, psicológicos, sociais e culturais ${ }^{1}$. Apesar de não apresentar níveis de prevalência elevados, esse transtorno vem sendo considerada um importante problema de saúde pública nos últimos anos ${ }^{2}$. A propósito, ao contrário do que se cogitava há algumas décadas, a ano- rexia nervosa não acomete somente adolescentes e jovens mulheres, mas também homens e crianças de ambos os $\operatorname{sexos}^{3}$. Além disso, não deve ser considerada uma patologia típica de nações ricas, visto que tem sido verificada em diferentes populações de países em desenvolvimento ${ }^{4}$.

Segundo os sistemas de classificação dos transtornos mentais vigentes, os aspectos psicopatológicos centrais da anorexia nervosa são o medo mórbido de engordar e o controle obsessivo do peso corporal ${ }^{5,6}$. Tal controle pode ser executado mediante o emprego 
de dietas extremamente restritivas ou a partir da utilização exacerbada de métodos purgativos ${ }^{7}$, que podem provocar um grave estado de inanição e desencadeia distúrbios endocrinológicos, gastrointestinais, cardiovasculares, hematológicos e metabólicos que contribuem para a manutenção e, em certos casos, cronificação do quadro, além de favorecer o desenvolvimento de patologias secundárias que podem até mesmo levar à morte ${ }^{1}$.

Outra característica psicopatológica importante na anorexia nervosa é a severa perturbação no modo de vivenciar o peso corporal ${ }^{5,6}$. Motivada pela autoavaliação centrada na forma física, essa perturbação provoca a negação dos riscos associados ao emagrecimento excessivo, fomentando, assim, a busca desenfreada da magreza ${ }^{7}$. Alguns autores propõem que a característica em questão deve ser considerada um critério operacional para o diagnóstico da anorexia nervosa ${ }^{8}$. É preciso reconhecer que não raro pacientes portadores de outras doenças psiquiátricas e até mesmo indivíduos normais apresentam uma percepção inapropriada de sua forma física ${ }^{9}$.

\section{2- Imagem corporal e anorexia nervosa}

A imagem corporal refere-se, em linhas gerais, à representação mental que cada indivíduo possui acerca de seu próprio corpo ${ }^{10}$. Moldada pela relação que o sujeito estabelece consigo mesmo e com seu ambiente, essa representação é construída e reconstruída incessantemente ao longo da vida. É possível afirmar, a partir dos resultados dos estudos disponíveis, que as experiências afetivas de um indivíduo desempenham um papel mais determinante para a constituição de sua imagem corporal do que as percepções objetivas referentes à sua forma física ${ }^{11,12}$. Seguindo essa linha de raciocínio, é possível postular que a imagem corporal não está vinculada ao corpo real, mas sim ao corpo simbólico, produto das experiências de trocas afetivas vivenciadas nos diferentes estágios do ciclo vital.

A qualidade da imagem corporal de um indivíduo se encontra intimamente associada à consistência de seu sistema de identidade. Esse sistema, por sua vez, é influenciado pelas representações das primeiras relações de objeto elaboradas durante a infância. As fantasias primárias, por um lado, e os vestígios mnêmicos precipitados a partir de experiências emocionais rudimentares de relacionamento com o corpo do outro e com o próprio corpo, por outro, são decisivos para o estabelecimento das referidas representações. Consequientemente, pode-se propor que a imagem corporal se destaca como uma importante faceta da personalidade, isto é, da organização afetiva e cognitiva que caracteriza o sujeito e determina sua conduta ${ }^{13}$. Sua gênese repousa no lastro de interações interpessoais vivenciadas, dentre as quais se destaca, pela especial importância que assumem para a estruturação das fundações da subjetividade, as experiências de ser cuidado por adultos (papel geralmente desempenhado pelos pais).

A qualidade e a constância dos cuidados dispensados à criança nos estágios mais precoces do desenvolvimento estruturam uma base segura que lhe permite organizar, gradualmente, um aparelho psíquico, graças ao qual ela logrará modular as necessidades pulsionais que emanam do corpo. As demandas afetivas passam, então, a ser elaboradas pela função simbólica, de maneira que aquilo que é vivenciado a partir do contato com as necessidades corporais - e que é da ordem da pulsão - pode aceder ao circuito das representações de palavra, ganhando assim uma inscrição psíquica. $\mathrm{O}$ acesso ao universo simbólico permite tanto o desenvolvimento afetivo como cognitivo, alicerçando o sentimento de identidade pessoal que confere ao ser humano a noção de que é único, singular e indivisível - ou, dito ao pé da letra: um indivíduo dotado de um psiquismo próprio, capaz de pensar os próprios pensamentos e conter os afetos que experimenta na sua relação consigo próprio e com o outro. Por esse motivo, a imagem corporal é uma dimensão constitutiva da identidade, que permite ao sujeito situar-se frente a si mesmo e ao mundo.

Tendo em vista as considerações teóricas que precedem, é possível cogitar que os conteúdos inconscientes são mais relevantes do que os elementos conscientes para a constituição da imagem corporal ${ }^{10}$. As técnicas projetivas se destacam como um recurso relevante para o estudo da imagem corporal, já que favorecem a emissão de respostas livres que subsidiam a investigação dos processos mentais profundos ${ }^{14,15}$. Isso ocorre basicamente porque, ao contrário dos testes psicométricos, as técnicas projetivas veiculam estímulos invariavelmente pouco estruturados e exigem do examinando um intenso grau de criação e elaboração pessoal.

A literatura científica especializada indica que pacientes portadores de anorexia nervosa - sobretudo do sexo feminino - geralmente superestimam o próprio tamanho e, desse modo, fazem uma avaliação extremamente negativa de sua aparência física. Também apresentam um acentuado temor de expor o pró- 
prio corpo, pois acreditam que inevitavelmente serão considerados obesos pelas demais pessoas ${ }^{16}$. Assim, pode-se propor que, com raras exceções, a anorexia nervosa se encontra intimamente associada a uma marcante distorção da imagem corporal ${ }^{17}$. Para diversos autores, essa distorção pode ser considerada um fator predisponente, precipitante e mantenedor da doença $\mathrm{a}^{9}$.

Questionários e escalas, dentre os quais se destacam o Body Shape Questionnaire, Body Dissatisfaction Scale, Body-SelfRelations Questionnaire e Body Image Avoidance Questionnaire, têm sido os instrumentos padronizados mais utilizados pelos pesquisadores responsáveis pelo estudo da imagem corporal na anorexia nervosa ${ }^{18}$. São auto-aplicáveis e permitem uma avaliação rápida, econômica e objetiva. Esses instrumentos possibilitam a expressão de sentimentos e comportamentos tidos como vergonhosos - tais como a ojeriza à gordura e a utilização de métodos purgativos - que poderiam ser mascarados em uma entrevista clínica. Por isso mostram-se de especial relevância para a adequada compreensão dos $\operatorname{casos}^{19}$.

Em contrapartida, essas estratégias de avaliação apresentam importantes limitações, uma vez que não viabilizam o acesso aos componentes inconscientes que são determinantes para a constituição da imagem corporal. Desse modo, a utilização de técnicas projetivas no estudo da imagem corporal na anorexia nervosa se destaca como um campo de trabalho extremamente promissor, já que, como salientam vários pesquisadores, os instrumentos desse tipo favorecem a apreensão de conteúdos psíquicos que se situam fora do plano consciente ${ }^{14,15,20 / 22}$. Partindo desse pressuposto, o presente estudo foi desenvolvido com o intuito de avaliar, mediante o emprego do Desenho da Figura Humana (DFH), a imagem corporal de mulheres anoréxicas, buscando averiguar suas dimensões inconscientes.

\section{2- MATERIAL E MÉTODOS}

\section{1- Participantes}

Participaram do presente estudo 10 mulheres anoréxicas vinculadas ao Grupo de Assistência em Transtornos Alimentares (GRATA) do Hospital das Clínicas da Faculdade de Medicina de Ribeirão Preto da Universidade de São Paulo (HC-FMRP-USP). Como indica o Quadro 1, a faixa etária das examinadas variou dos 19 aos 33 anos de idade (média de 26,5 anos). A maioria das participantes apresentava os sintomas característicos do subtipo purgativo da doença, era solteira com escolaridade superior. Nenhuma apresentava déficit intelectual suspeitado.

\section{Quadro 1: Caracterização sociodemográfica e diagnóstico das participantes do presente estudo.}

\begin{tabular}{|l|l|l|l|l|}
\hline Paciente & Idade & Escolaridade & Estado civil & Diagnóstico \\
\hline Paula & 31 anos & Ensino médio completo & Casada & Anorexia (subtipo restritivo) \\
\hline Maria & 33 anos & Ensino superior incompleto & Casada & Anorexia (subtipo restritivo) \\
\hline Fernanda & 26 anos & Ensino fundamental completo & Casada & Anorexia (subtipo purgativo) \\
\hline Joana & 24 anos & Ensino superior completo & Solteira & Anorexia (subtipo purgativo) \\
\hline Amanda & 29 anos & Ensino médio completo & Solteira & Anorexia (subtipo restritivo) \\
\hline Natália & 30 anos & Ensino médio incompleto & Casada & Anorexia (subtipo purgativo) \\
\hline Renata & 19 anos & Ensino superior incompleto & Solteira & Anorexia (subtipo restritivo) \\
\hline Lívia & 22 anos & Ensino superior incompleto & Solteira & Anorexia (subtipo purgativo) \\
\hline Jaqueline & 23 anos & Ensino superior incompleto & Solteira & Anorexia (subtipo purgativo) \\
\hline Sabrina & 28 anos & Ensino superior incompleto & Solteira & Anorexia (subtipo purgativo) \\
\hline
\end{tabular}




\section{2- Instrumentos}

As mulheres em questão foram submetidas à aplicação de uma série de instrumentos de avaliação psicológica antes do início do tratamento oferecido pelo GRATA. O presente estudo, porém, aborda especificamente os dados coligidos mediante a utilização do Desenho da Figura Humana (DFH). Trata-se de uma técnica projetiva gráfica de aplicação relativamente simples: a tarefa proposta consiste em solicitar ao examinando o desenho de uma figura humana e, em seguida, o desenho de uma figura humana do sexo oposto ao da primeira. Os materiais empregados para tanto são um lápis preto e folhas de papel em branco tamanho ofício. Após a coleta dos desenhos, um inquérito específico é utilizado com o intuito de complementar a atividade gráfica com a comunicação verbal ${ }^{23}$.

Optou-se por focalizar no presente estudo os resultados oriundos da utilização do DFH em função de uma série de razões. Em primeiro lugar, o tema da figura humana remete às imagens internalizadas que o sujeito tem de si mesmo, de maneira que fornece elementos profícuos para a compreensão de aspectos inconscientes da imagem corporal do examinando ${ }^{22,24}$. Em segundo lugar, o DFH, por privilegiar a comunicação gráfica, dificulta o emprego dos mecanismos de defesa usualmente adotados de forma consciente durante a aplicação de técnicas verbais ${ }^{25,26}$. Em terceiro lugar, a técnica em questão é econômica e de aplicação rápida ${ }^{27,28}$. Em quarto lugar, a tarefa proposta usualmente é bem aceita por indivíduos que apresentam dificuldades de expressão verbal ou baixo nível educacional $^{11}$.

\section{3- Técnica de coleta de dados}

A coleta de dados foi realizada individualmente em uma sala reservada e com condições adequadas nas instalações do HC-FMRP-USP. As participantes executaram os desenhos com lápis preto em folhas de papel branco tamanho ofício sobre uma mesa razoavelmente ampla e plana - capaz de permitir o apoio dos braços em sua superfície - e permaneceram sentadas em uma cadeira confortável. Assim, puderam adotar uma postura natural de relaxamento, o que permite supor que qualquer indício de tensão psíquica projetado nas produções gráficas é endógeno, e não imposto pela situação física externa ${ }^{28}$.

As recomendações técnicas preconizadas pela literatura científica especializada foram adotadas como referencial para a coleta dos desenhos. As instruções apresentadas foram, em linhas gerais, as seguintes: "Por favor, desenhe uma figura humana", "Por favor, desenhe uma figura humana do sexo oposto ao daquela que você acabou de desenhar" e "Agora por favor responda a algumas perguntas referentes às figuras que você acabou de desenhar". As folhas de papel foram colocadas verticalmente diante dos sujeitos. Além disso, vale destacar que os mesmos foram informados de que poderiam utilizar uma borracha caso considerassem necessário ${ }^{23}$

Adotou-se como norma aceitar os desenhos incompletos e estereotipados, uma vez que a ocorrência de produções com tais características pode indicar a existência de conflitos relacionados à área negligenciada e seus significados simbólicos. A aplicação do inquérito teve início depois da execução da etapa gráfica da tarefa. As questões propostas pela literatura científica especializada ${ }^{11}$ foram utilizadas nesse processo. Foram levadas em consideração as recomendações preconizadas pelas resoluções federais que estabelecem os cuidados éticos a serem observados em pesquisas envolvendo seres humanos. $\mathrm{O}$ presente estudo contou com a aprovação do Comitê de Ética em Pesquisa do HC-FMRP-USP.

\section{4- Técnica de análise dos dados}

A análise dos dados foi dividida em duas etapas distintas. Na primeira delas, o conjunto do material obtido foi examinado às cegas e de maneira independente por dois juízes especializados (psicólogos pósgraduados com experiência prévia no manejo de técnicas projetivas gráficas) com o intuito de evitar a contaminação dos resultados com informações prévias sobre os sujeitos e sobre o quadro psicopatológico que apresentam. O trabalho dos juízes foi executado a partir do emprego de um protocolo desenvolvido especialmente para o presente estudo. Baseado nos critérios preconizados pela literatura científica especializada $^{11,23 / 30}$, tal protocolo é composto por 46 indicadores e 244 unidades de cotação, de modo que compreende tanto os aspectos gerais e formais quanto os elementos específicos das produções gráficas.

As unidades de cotação avaliadas consensualmente pelos juízes foram automaticamente consideradas. Já as unidades de cotação avaliadas de modo conflitante foram discutidas caso a caso. Depois da conclusão do trabalho dos juízes, foi calculado o índice de concordância da avaliação dos desenhos mediante a utilização da fórmula ACORDO $=\Sigma$ Concor- 
dância real - Discordância real / Unidades de cotação. Os valores obtidos variaram de 0,68 a 0,91 (média de 0,80$)$. Tomando-se como base os parâmetros fornecidos pela literatura científica especializada ${ }^{31,32}$, esses índices podem ser considerados satisfatórios.

$\mathrm{Na}$ segunda etapa de análise, o pesquisador, pautando-se no trabalho dos juízes, submeteu o material a uma análise interpretativa, pois a maioria dos pesquisadores responsáveis pelos avanços das técnicas projetivas gráficas considera esta estratégia de avaliação mais reveladora - ainda que menos objetiva - do que o exame quantitativo ${ }^{25,29}$. Os estudos que forneceram as diretrizes para a elaboração do protocolo de avaliação também foram empregados nesse processo. Entretanto, alguns desses estudos são apoiados em bases empíricas questionáveis ${ }^{33}$. Em que pesem essas limitações, subsidiam a atribuição de significados a diversos aspectos das produções gráficas, o que justifica sua utilização, desde que se tome a devida cautela.

Com o intuito de conferir maior fidedignidade às interpretações, levou-se em consideração a convergência dos indícios verificados nos diferentes desenhos e, conseqüentemente, foi executada uma avaliação global do conjunto das produções coletadas. Esse procedimento é considerado de extrema importância, tendo em vista que um único aspecto de uma figura jamais possui, por si só, um significado específico e tampouco reflete necessariamente traços da personalidade do sujeito que a produziu, pois, como apontam diversos autores, as características de um desenho são influenciadas não apenas por fatores psicológicos, mas também por variáveis sociais e culturais ${ }^{11,34}$.

\section{3- RESULTADOS}

A análise das produções gráficas obtidas indica que as pacientes avaliadas apresentam uma preocupação exacerbada com a própria aparência, como ilustra a Figura 1. Além disso, fazem uma auto-avaliação demasiadamente centrada na forma física e, a despeito da magreza patológica, temem engordar, conforme revela o Quadro 2. Como consequiência, mostram-se claramente insatisfeitas consigo mesmas. O fato de a maior parte das mulheres em questão ter desenhado crianças ao invés de figuras humanas adultas pode ser entendido como um reflexo dessa insatisfação, visto que sugere que elas não são capazes de se aceitarem e, desse modo, se caracterizam por uma marcante fixação a etapas anteriores do desenvolvimento psico-afetivo.

A representação mental que as participantes do presente estudo têm de si mesmas também parece ser influenciada por sentimentos de inferioridade e inadequação associados a uma acentuada fragilidade egóica, uma vez que a maioria das figuras humanas coligidas é de tamanho diminuto, pouco integrada e pobre em detalhes. Essa influência provavelmente ocorre de modo inconsciente, pois fomenta a utilização de mecanismos de defesa arcaicos que produzem uma imagem corporal compensatória - como se vê na Figura 2 - e indicam que o psiquismo das examinadas opera sob a égide do narcisismo primário. Mas, tal narcisismo é predominantemente voltado para compensar um marcado déficit de auto-estima, resultado de uma imagem de si mal integrada e primitiva, caracterizando, assim um narcisismo de morte, e não a serviço da vida.

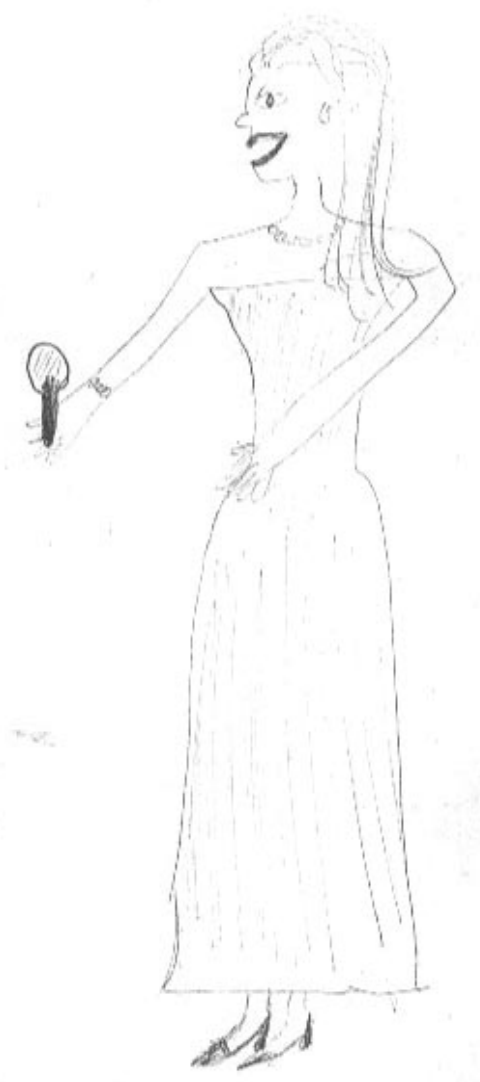

Figura 1: Figura humana feminina executada por Joana. $O$ fato de a figura humana feminina desenhada estar observando o reflexo de sua imagem em um espelho sugere uma preocupação exacerbada com a própria aparência e pode ser entendido como um indício de narcisismo primário. 
Quadro 2: Respostas ao inquérito referente à figura humana feminina executada por Maria.

\begin{tabular}{|c|c|}
\hline Perguntas & Respostas \\
\hline Qual é a idade dessa pessoa? & 20 anos. \\
\hline Onde ela está? & Passeando. \\
\hline O que ela está sentindo? & Nada, ela está se sentindo bem. \\
\hline Do que ela gosta? & De aproveitar a vida. \\
\hline Do que ela não gosta? & De se sentir sozinha, de sentir feia, de se sentir gorda. \\
\hline Essa pessoa tem boa saúde? & Tem. \\
\hline Do que essa pessoa tem medo? & De ficar velha, de ficar sozinha, de ficar feia, de ficar gorda. \\
\hline O que vai acontecer com ela? & Vai acontecer tudo o que ela tem medo. \\
\hline O que faria essa pessoa mais feliz? & Não sentir medo. \\
\hline Quais são os três maiores desejos dessa pessoa? & $\begin{array}{l}\text { Se sentir amada e bonita, ser boa mãe e boa esposa e não } \\
\text { ter problema de saúde. }\end{array}$ \\
\hline Quais são os principais defeitos dessa pessoa? & Ela tem uns defeitos físicos por causa de já ter sido gorda. \\
\hline Quais são as principais qualidades dessa pessoa? & $\begin{array}{l}\text { Ela nunca pensa mal de ninguém, ela gosta de ver todo } \\
\text { mundo bem. }\end{array}$ \\
\hline Qual é a parte do corpo que essa pessoa menos gosta? & Toda a parte do tronco. \\
\hline Qual é a parte do corpo que essa pessoa mais gosta? & Ela só gosta dos olhos. \\
\hline
\end{tabular}

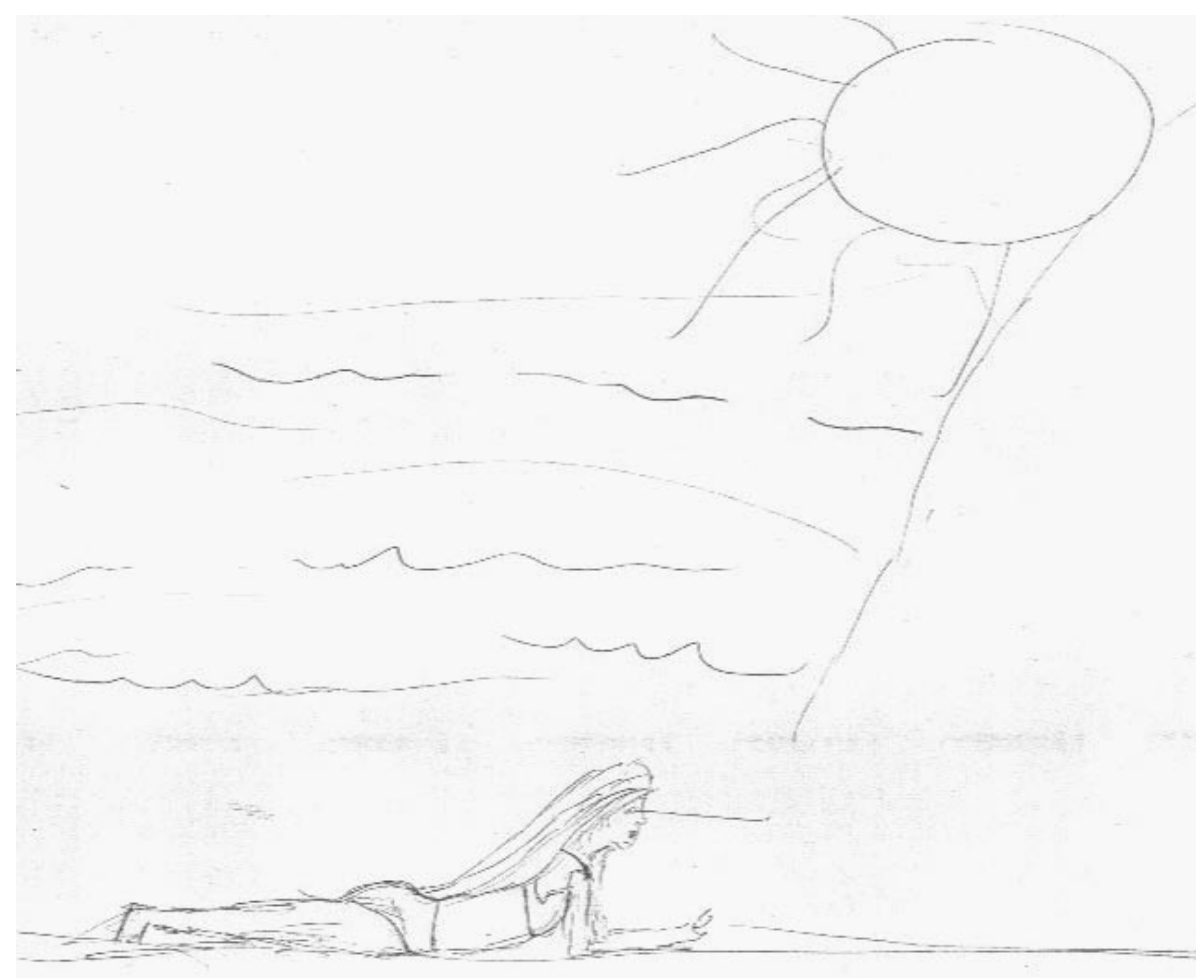

Figura 2: Figura humana feminina executada por Natália.

O fato de a figura humana feminina desenhada estar se bronzeando aponta que a paciente em questão faz uma auto-avaliação demasiadamente centrada na forma física e possui uma imagem corporal compensatória. 
Pode-se postular que a referida fragilidade egóica tende a provocar um sentimento de insegurança no contato com o mundo exterior, pois as mãos na maioria das produções se encontram desconfiguradas. Seguindo esse raciocínio, é plausível cogitar que as mulheres em questão são propensas à passividade e apresentam uma importante restrição do potencial adaptativo. Já o tamanho e o formato do pescoço dos desenhos sugerem que os impulsos - sobretudo sexuais das mesmas são controlados de modo obsessivo, o que pode causar uma severa perda da libido. Não obstante, esse controle depende do emprego de uma grande quantidade de energia psíquica, de modo que não raro se torna impraticável. Quando essa defesa, baseada no controle rígido sobre os impulsos, entra em exaustão, essas pacientes ficam próximas de um colapso das fronteiras narcísicas que sustentam a coesão da identidade e se tornam vulneráveis à depressão.

Essa hipótese ganha maior sustentação levando-se em conta que os cabelos da maioria das figuras são escassos e desordenados. Os traços faciais simplificados verificados no conjunto do material coletado apontam que as participantes do presente estudo tendem à introversão e ao retraimento, de modo que usualmente mantêm relacionamentos sociais, familiares e amorosos superficiais. Em contrapartida, a ocorrência de botões e bolsos nas roupas dos desenhos - tal como se nota na Figura 3 - revela necessidades latentes de afiliação. Por fim, as correções e os retoques executados repetidamente ao longo da tarefa podem ser entendidos como indícios de ansiedade e perfeccionismo, que na anorexia são direcionados para a relação com o próprio corpo.

\section{4- DISCUSSÃO}

Em linhas gerais, os resultados obtidos são compatíveis com os achados da literatura científica especializada, já que diversas pesquisas indicam que a imagem corporal de pacientes anoréxicas apresenta uma marcante distorção decorrente de sentimentos de inferioridade desencadeados por uma preocupação patológica com a própria forma física ${ }^{9,16,17}$. O presente estudo indica que as mulheres em questão possuem uma acentuada fragilidade egóica, são propensas à utilização de mecanismos de defesa arcaicos, caracterizam-se por uma restrição do potencial adaptativo, controlam os próprios impulsos com excessivo rigor e tendem à passividade, à introversão, à obsessividade e à dependência.

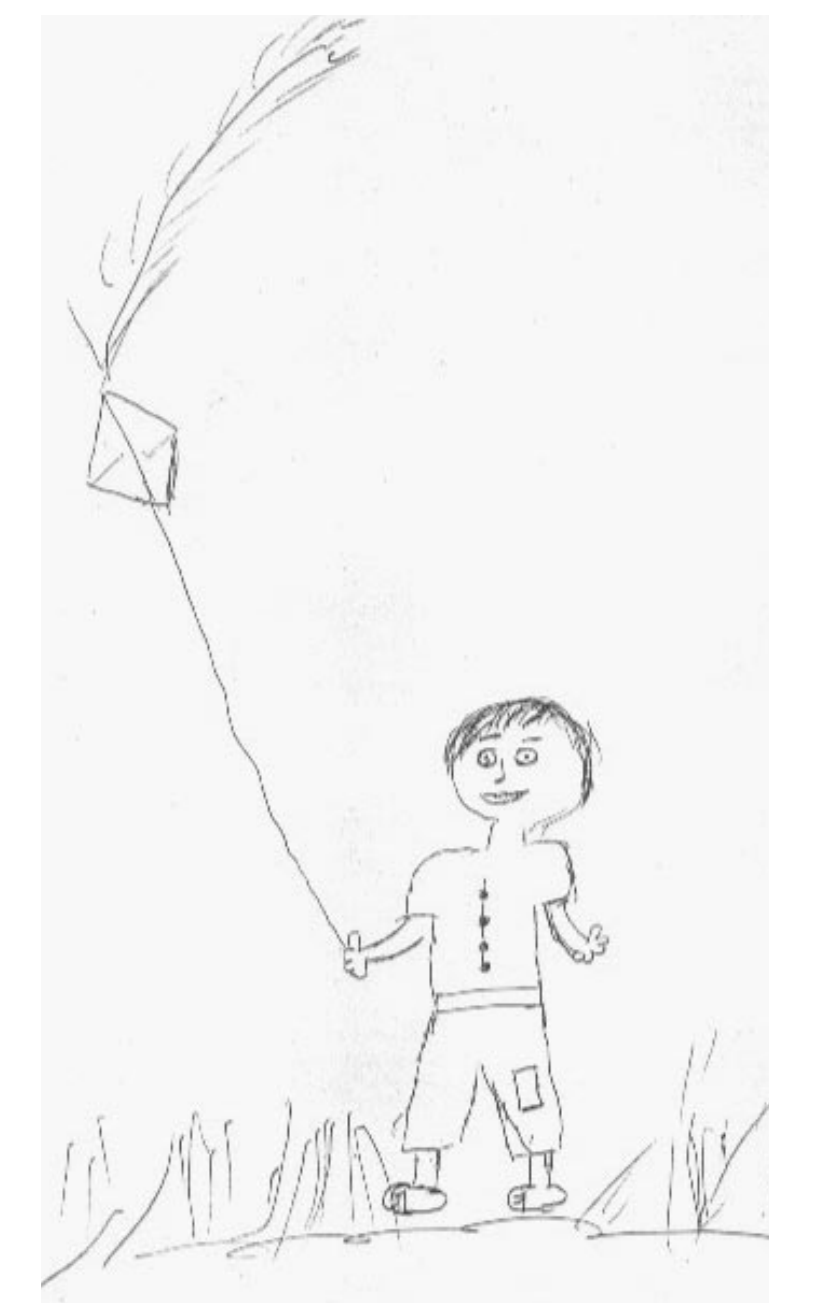

Figura 3: Figura humana masculina executada por Amanda. $O$ fato de a figura humana masculina desenhada ser uma criança sugere que a paciente em questão se caracteriza por uma fixação a etapas anteriores do desenvolvimento - possivelmente em função de não aceitar a representação interna que possui acerca do próprio corpo.

Tais características também foram descritas por outros autores que se dedicam ao assunto, de modo que podem ser consideradas freqüentes na anorexia nervosa $^{1,2,3,35,36}$, mas dificilmente podem ser identificadas a partir da aplicação de instrumentos psicométricos, visto que muitas delas são inconscientes.

Conclui-se, assim, que o DFH se mostrou adequado frente ao objetivo proposto, pois possibilitou a projeção de conteúdos internos situados para além do plano da consciência, que exercem papel determinante na constituição da imagem corporal e somente poderiam ser apreendidos mediante a utilização de métodos mais dispendiosos.

Por outro lado, o DFH apresenta certas limitações, uma vez que a maioria dos estudos que esta- 
belece critérios para a análise interpretativa do material oriundo de sua aplicação se apóia em bases empíricas questionáveis ${ }^{33}$. As características de uma produção gráfica não necessariamente revelam aspectos da imagem corporal ou da personalidade do indivíduo que a executou, visto que podem ser influenciadas por diversas variáveis, tais como estereótipos culturais, determinantes sociais, fatores de gênero e condições ambientais $^{11,34}$. Por isso, a adequada avaliação dos desenhos se encontra intimamente relacionada à experiência do examinador no manejo do instrumento, $\mathrm{o}$ que sem dúvida restringe suas possibilidades de utilização.

Devido a essas limitações, as hipóteses baseadas na análise das produções gráficas coligidas a partir da aplicação do DFH devem ser complementadas com os resultados obtidos a partir do emprego de técnicas de avaliação mais objetivas. A literatura científica especializada aponta que a combinação de diferentes instrumentos se faz necessária para que se possa executar uma avaliação psicológica fidedigna, uma vez que, em última análise, qualquer recurso passível de ser utilizado nesse processo apresenta restrições $^{20,22}$. Essa necessidade, torna-se ainda mais acentuada quando se trabalha com construtos teóricos complexos e multifacetados como a imagem corporal.

Negar a validade das hipóteses baseadas na análise interpretativa dos desenhos oriundos da aplicação do DFH tomando-se como parâmetro os critérios positivistas de objetividade máxima preconizados pelas ciências naturais é uma falácia, uma vez que o universo psíquico de examinado, objeto da referida técnica, não pode ser observado ou medido diretamente $^{15}$. Pode-se afirmar, em última análise, que a proficuidade do instrumento em questão - e, em um sentido mais amplo, das técnicas projetivas de modo geral - encontra-se intimamente vinculada à inexistência de vias de acesso mais objetivas ao conhecimento visado ${ }^{21}$.

Segundo vários autores, o comprometimento da imagem corporal que caracteriza os portadores de anorexia nervosa pode ser entendido como uma condição associada ao desenvolvimento e à manutenção do transtorno ${ }^{9,16}$. Essa hipótese se torna mais consistente levando-se em consideração que, como discutido anteriormente, diversos estudos apontam que determinantes subjetivos - moldados de acordo com os recursos e limites da personalidade do sujeito - exercem maior influência no complexo e permanente pro- cesso de representação mental do próprio corpo do que a realidade objetiva da aparência física ${ }^{10,12}$. Esse achado evidenciado pela literatura é reiterado diariamente na clínica dos transtornos alimentares. Assim, a distorção da imagem corporal projetada nos desenhos coletados não deve ser entendida apenas como um efeito da anorexia nervosa.

Além disso, os distúrbios da imagem corporal não são patognomônicos da anorexia nervosa, já que ocorrem também em outros quadros psiquiátricos e até mesmo em indivíduos normais ${ }^{8,9}$. Pesquisas recentes indicam que o imperativo da magreza instituído pela cultura ocidental tem tornado cada vez mais freqüente a insatisfação patológica com a própria forma física, fomentando, como conseqüência, a eclosão de transtornos do comportamento alimentar ${ }^{2,17,37}$. Nesse sentido, a distorção da imagem corporal apresentada pelas participantes do presente estudo pode ser considerada o resultado da combinação de fatores psicológicos e determinantes sócio-culturais.

\section{5- CONSIDERAÇÕES FINAIS}

O DFH permitiu o acesso a importantes aspectos inconscientes da imagem corporal das examinadas e, desse modo, contribuiu, ainda que indiretamente, para o aprimoramento da assistência multidisciplinar dispensada às mesmas. Os resultados obtidos são congruentes com os achados da literatura científica especializada, visto que diversos autores salientam o valor desse instrumento no estudo dos processos mentais profundos necessário para o planejamento terapêutico $^{38 / 44}$. Em contrapartida, é preciso enfatizar novamente que o DFH apresenta limitações que restringem seu alcance e não devem ser ingenuamente desconsideradas. Tais limitações, não inviabilizam sua utilização como instrumento de avaliação psicológica.

O presente estudo indica também que a distorção da imagem corporal das mulheres examinadas encontra-se intimamente relacionada a diversos outros transtornos psicológicos. Evidencia-se, assim, a necessidade de um tratamento multidisciplinar voltado não apenas à recuperação do peso, mas também à compreensão dos aspectos emocionais relacionados à gênese e à perpetuação da anorexia nervosa, já que a ocorrência de comorbidade tende a acelerar o curso da doença ${ }^{35}$. Partindo desse princípio, uma equipe composta por profissionais de diferentes especialidades (um clínico geral com especialização em nutrologia, 
um nutricionista, um psicólogo e um psiquiatra) pode ser entendida como um pré-requisito para a abordagem integrada dessa problemática.

Ressalte-se que, dentre as diversas práticas psicológicas existentes, a psicoterapia psicodinâmica se destaca como um recurso potencialmente funcional no tratamento da anorexia nervosa, pois tem como propósito básico favorecer a resolução de conflitos psíquicos e promover, como conseqüência, a reorganização da personalidade ${ }^{45}$. Por essa razão, pode levar o portador da enfermidade em questão a obter uma melhor compreensão de sua condição física e emocional e a desenvolver uma maior capacidade de manejo de seus afetos. Como resultado desse processo, cria condições propícias para o resgate da autoestima e para a reestruturação da imagem corporal $^{46}$.

Peres RS, Santos MA. Human figure drawing contributions for body image assessment in anorexia nervosa. Medicina (Ribeirão Preto) 2006; 39 (3): 361-70.

ABSTRACT: The present study was developed to evaluate the body image of anorexia nervosa patients. The Human Figure Drawing (HFD) was used as instrument, because is a graphic projective technique that makes possible the investigation of the deep psychological processes and the mental representation of himself. A number of 10 anorexic women treated at Grupo de Assistência em Transtornos Alimentares (GRATA) from HC-FMRP-USP were assessed. The collected material was evaluated in accordance with the procedures described at the scientific literature. The results indicate that part of the appraised women presents a negative body image, permeated clearly by inferiority, inadequacy, and insecurity feelings. However, some participants projected in the drawings an idealized body image, influenced directly by compensatory mechanisms of defense. Such results indicate that HFD can be considered a useful technique for body image evaluation in anorexia nervosa and a valuable alternative to the psychometrics instruments usually employed with this purpose.

Keywords: Anorexia Nervosa. Body Image. Psychological Assessment.

\section{REFERÊNCIAS}

1 - Morgan CM, Vecchiatti IR, Negrão AB. Etiologia dos transtornos alimentares: aspectos biológicos, psicológicos e sócioculturais. Rev Bras Psiquiatr 2002; 24 (Supl III): 18-23.

2 - Bucaretchi HA, Cordás, TA. Distúrbios alimentares: anorexia e bulimia. In: Quayle J, Lucia MCS, eds. Adoecer: as interações do doente com sua doença. São Paulo: Atheneu; 2003. p. $49-60$.

3 - Salzano FT, Cordás TA. Transtornos alimentares. In: Cordás TA, Salzano FT, eds. Saúde mental da mulher. São Paulo: Atheneu; 2004. p. 201-28.

4 - Hay, PJ. Epidemiologia dos transtornos alimentares: estado atual e desenvolvimentos futuros. Rev Bras Psiquiatr 2002; 24 (Supl III): 13-7.

5 - Organização Mundial da Saúde. Classificação de transtornos mentais e de comportamento da CID-10: descrições clínicas e diretrizes diagnósticas. Trad. D Caetano. Porto Alegre: Artes Médicas; 1993.

6 - American Psychiatric Association. Manual diagnóstico e estatístico de transtornos mentais. 4aㅡ edição. Trad. D Batista. Porto Alegre: Artes Médicas; 1994.
7 - Cordás TA. Transtornos alimentares: classificação e diagnóstico. Rev Psiquiatr Clin 2004; 31 (4): 154-7.

8 - Claudino AM, Borges MBF. Critérios diagnósticos para os transtornos alimentares: conceitos em evolução. Rev Bras Psiquiatr 2002; 24 (Supl III): 7-12.

9 - Saikali CJ, Soubhia CS, Scalfaro BM, Cordás TA. Imagem corporal nos transtornos alimentares. Rev Psiquiatr Clin 2004; 31 (4): 164-6.

10 - Schilder P. A imagem do corpo. Trad. R Wertman. São Paulo: Martins Fontes; 1994.

11 - Lourenção Van Kolck O. Testes projetivos gráficos no diagnóstico psicológico. São Paulo : EPU; 1984.

12 - Dalgalarrondo P. Psicopatologia e semiologia dos transtornos mentais. Porto Alegre: Artes Médicas; 2000.

13 - Bruchon-Scheweitzer M. Image du corps et personnalité: la perception de huit zones corporelles d'après le Body Focus Questionnaire de Fisher. Psychol Franç 1982; 27 (2), 66-77.

14 - Anzieu D. Os métodos projetivos. Trad. MLE Silva. Rio de Janeiro: Campus; 1978. 
15 - Güntert AEVA. Técnicas projetivas: o geral e o singular em avaliação psicológica. In: Sisto FF, Sbardelini ETB, Primi R, eds. Contextos e questões da avaliação psicológica. São Paulo: Casa do Psicólogo; 2000. p. 77-84.

16 - Cash TF, Deagle EA. The nature and extent of body image disturbances in anorexia nervosa and bulimia. Int J Eat Disord 1997; 22, 107-25.

17 - Straub, RO. Nutrição, obesidade e transtornos da alimentação. In: Straub, RO. Psicologia da saúde. Trad. RC Costa. Porto Alegre; Artes Médicas, 2005. p. 231-69.

18 - Cordás TA, Neves JEP. Escalas de avaliação de transtornos alimentares. In: Gorenstein C, Andrade LHSG, Zuardi AW, eds. Escalas de avaliação clínica em psiquiatria e psicofarmacologia. São Paulo: Lemos; 2000. p. 345-7.

19 - Freitas S, Gorenstein C, Appolinario JC. Instrumentos para a avaliação dos transtornos alimentares. Rev Bras Psiquiatr 2002; 24 (Supl III): 34-8.

20 - Cunha JA. Estratégias de avaliação: perspectivas em psicologia clínica. In: Cunha JA, ed. Psicodiagnóstico-V. Porto Alegre: Artes Médicas; 2000. p.19-22.

21 - Silva MLE. Interpretação de testes projetivos: projeção e representação. Rio de Janeiro: Campus; 1981.

22 - Lourenção Van Kolck O. Técnicas de exame psicológico e suas aplicações no Brasil. Petrópolis: Vozes; 1981.

23 - Machover K. Proyeccion de la personalidad en el dibujo de la figura humana. Trad. JM Gutierrez. Havana: Cultural; 1962.

24 - Portuondo J. Test proyectivo de Karen Machover. Madrid: Biblioteca Nueva; 1973.

25 - Arzeno MEG. Psicodiagnóstico clínico. Trad. BA Neves. Porto Alegre: Artes Médicas; 1995.

26 - Piccolo EG. Os testes gráficos. Trad. M Felzenszwalb. In: Ocampo MLS, Arzeno MEG, Piccolo EG, eds. O processo psicodiagnóstico e as técnicas projetivas. São Paulo: Martins Fontes; 1981. p. 203-311.

27 - Campos DMS. O teste do desenho como instrumento de diagnóstico da personalidade. Petrópolis: Vozes; 1998.

28 - Levy S. Desenho projetivo da figura humana. Trad. E Nick. In: Hammer EF, ed. Aplicações clínicas dos desenhos projetivos. Rio de Janeiro: Interamericana; 1981. p. 61-85.

29 - Grassano E. Indicadores psicopatológicos nas técnicas projetivas. Trad. LSPC Tardivo. São Paulo: Casa do Psicólogo; 1996.

30 - Cunha JA. Técnicas projetivas gráficas: por que sim? por que não? São Paulo: Casa do Psicólogo; 2000.

31 - Anastasi A, Urbina S. Testagem psicológica. Trad. MAV Veronese. Porto Alegre: Artes Médicas; 2000.
32 - Fachel JMG, Camey S. Avaliação psicométrica: a qualidade das medidas e o entendimento dos dados. In: Cunha JA, ed. Psicodiagnóstico-V. Porto Alegre: Artes Médicas; 2000. p.158-70.

33 - Hutz CS, Bandeira DR. Avaliação psicológica com o Desenho da Figura Humana: técnica ou intuição? Temas Psicol 1995; 3: 35-41.

34 - Souza AMDR. Implicação do fator cultural regional nos desenhos da figura humana (DFH) produzidos por sujeitos adultos: análise da diferenciação sexual e de aspectos projetivos. [Tese de Doutorado], São Paulo: Instituto de Psicologia - USP; 2000.

35 - Martins FCO, Sassi Júnior E. A comorbidade entre transtornos alimentares e de personalidade e suas implicações clínicas. Rev Psiquiatr Clin 2004; 31 (4): 161-3.

36 - Grilo CM. Recent research of relationships among eating disorders and personality disorders. Curr Psychiatry Rep 2002; 4 (1): 18-24.

37 - Pinhas L, Toner BB, Ali A, Garfinkel PE, Stuckless N. The effects of the ideal of female beauty on mood and body satisfaction. Int J Eat Disord 1999; 25 (2): 223-6.

38 - Lourenção Van Kolck O, Jaehn SM. O desenho da figura humana de crianças com distúrbios de linguagem. Rev Bras Pesq Psicol 1990; 2 (3): 41-4.

39 - Lourenção Van Kolck O, Neder, CR. A imagem corporal em tentativas de suicídio por ingestão de substâncias cáusticas. Rev Bras Pesq Psicol 1991; 3 (3), 39-45.

40 - Lourenção Van Kolck O, Tosi SMVD, Pellegrini TF. Autoimagem em alcoólicos crônicos. Temas 1991; 21 (42), 37482.

41 - Hojaji EM, Romano BW. Modificação da imagem corporal ao longo do processo de transplante cardíaco. Rev Soc Cardiol Est São Paulo 1995; 5 (6 Supl A), 9-16.

42 - Tardivo LSPC, Fráguas Júnior R, Rizzini MA, Paulo MSLL. Os desenhos da figura humana em pacientes com depressão secundária. Mudanças 1999; 7 (11), 223-34.

43 - Santos MA, Peres RS, Benez MSL. Contribuições do Desenho da Figura Humana para o delineamento do perfil psicológico de um grupo de obesos mórbidos. Psic 2002; 3 (2), 20-9.

44 - Almeida GAN, Loureiro SR, Santos JE. A imagem corporal de mulheres morbidamente obesas avaliadas através do desenho da figura humana. Psicol Refl Crít 2002; 15 (2), 283-92.

45 - Fiorini HJ. Teoria e técnica de psicoterapias. Trad. C Sussekind. Rio de Janeiro: Francisco Alves; 1981.

46 - Gorgati SB, Holcberg AS, Oliveira MD. Abordagem psicodinâmica no tratamento dos transtornos alimentares. Rev Bras Psiquiatr 2002; 24 (Supl III): 44-8. 